\title{
ANJOS E DEMÔNIOS EM GIL VICENTE E JOSÉ DE ANCHIETA: ALEGORIA E ACULTURAÇÃO
}

Dulce M. Viana Mindlin

Depois chegávamos nós por ouvir falar do caso e procurávamos alguém que ainda não tivesse perdido a memória. Encontrávamos as testemunhas, mas Aldegundes, por exemplo, já não sabia como voava um pássaro.

\author{
LIDIA JORGE \\ ( $O$ cais das merendas)
}

\section{RESUMO}

Estudo do Auto da alma, de Gil Vicente, e do auto Na aldeia de Guarapari, de José de Anchieta, focalizando a alegorização como recurso perfeito de um teatro voltado para o reforço do status quo europeu, e portanto de sua hegemonia política e religiosa. A exploração do maniqueísmo. As consequiências da aculturação como desenraizamento e perda da memória cultural.

O texto em epígrafe, de uma das mais festejadas romancistas portuguesas da atualidade, aponta para um problema dos mais perturbadores, quaisquer que sejam as culturas postas na berlinda: o incômodo da colonização, como vemos, não é privilégio dos que vivem abaixo do Equador. No caso português, em pleno século XX, um livro como $O$ cais das merendas é espaço de representação de questões absolutamente vitais - no caso, a identidade cultural - cuja discussão é considerada em prioridade, mormente em tempos de CEE, quando, de certa forma, o problema há de ter sido discutido: a patética frase final do romance é forte o bastante para que o leitor se sinta profundamente tocado pelo desenraizamento cultural da personagem que, desse ponto de vista, passa pela experiência da morte, ainda que simbólica.

Estas considerações me vêm a propósito de estudos que venho desenvolvendo sobre o século XVI, seja na literatura portuguesa, seja na literatura brasileira. E nesta, o colonialismo acaba ganhando papel de fundamental importância, na medida em que é ele uma das melhores claves de leitura de textos aparentemente 'inocentes', como os de José de Anchieta, 
mas que revelam, numa leitura mais atenta, todas as nuances de um projeto não apenas religioso, como à primeira vista poderia parecer, mas ainda - e principalmente - político-econômico, em todas as suas maléficas e perversas facetas: é preciso não esquecer que a catequese se inscrevia exemplarmente no sistema de Patronato que, como se sabe, é a configuração da excelência nas relações da Igreja com a Coroa.

No caso português, como no espanhol, o Patronato ficou conhecido como Patronato Real, e seu desenvolvimento tem, a mais direta das relações com a expansão ultramarina e a fundação de impérios coloniais. Num tal contexto, o projeto catequético da Companhia de Jesus viria a funcionar como uma luva: de um lado, atendendo aos ideais inacianos de "educar os rudes"; de outro, atendendo tanto à implantação como à consolidação do projeto português em terras brasis - um projeto, como não deixam dúvida os documentos, de absoluta 'idéia fixa' no qual os fins justificam todos os meios, uns mais violentos, outros menos, porém com um denominador comum bastante nítido: a 'lavagem cerebral' que possibilitaria à Igreja dos tempos da Contra-Reforma uma reabilitação bastante significativa via expansão da fé católica e que, last but not least, propiciaria à Coroa uma tranqüilidade maior na instalação de um império de além-mar. Dentre esses meios, destaca-se o teatro de José de Anchieta como elemento aliciador, educador, consolidador. E neste, ratificando a excelência do seu didatismo, o uso e o abuso das alegorias, uma vez que, na concretização dos elementos abstratos como a Morte, o Diabo, a Alma etc., era possível passar toda uma visão de mundo que pretendia, antes de mais nada, dominar para subjugar - e isso segundo as palavras do próprio Pe. Manuel da Nóbrega: "para o bem da Coroa, é melhor serem cristãos e estarem sujeitos." Num tal contexto, as figuras dos Anjos e dos Diabos adquiriam uma funcionalidade a toda prova: eram representações perfeitas de relações maniqueístas que necessitavam de uma veiculação que não suscitasse a menor dúvida.

É verdade que a presença desse anjos e diabos em autos de cunho religioso não é a coisa mais original do mundo - no caso de Anchieta, é por demais nítida a herança de Gil Vicente, tanto nas formas como nos conteúdos manifestos ou latentes. Mas vamos por partes. Permitamo-nos um primeiro momento de estudo de textos, feita de antemão uma escolha, a circunstância do "diálogo de limiar", que privilegia aquelas alegorizações: o Auto da Alma, de Gil Vicente e o auto Na aldeia de Guarapari, de José 
de Anchieta, embora outros anjos e outros diabos povoem intermitentemente muitos dos demais autos de ambos os autores.

Gil Vicente, ao pôr em cena anjos e diabos a seduzirem a alma recémliberta do corpo, vai atualizar toda uma visão de mundo ainda medieval, apesar de sua época, na qual aquele mencionado maniqueísmo adquire força bastante expressiva, na medida em que aparece representado concretamente por figuras que o senso comum já consagrara como emblemáticas do Bem e do Mal - e talvez seja por essa razão que de modo geral não se discute o papel de sedutor desempenhado pelo anjo, por exemplo, no Auto da Alma, modificando a interpretação mais simplista que considera apenas o diabo como o que tenta aliciar a alma através da concessão de bens materiais e objetos de luxo:

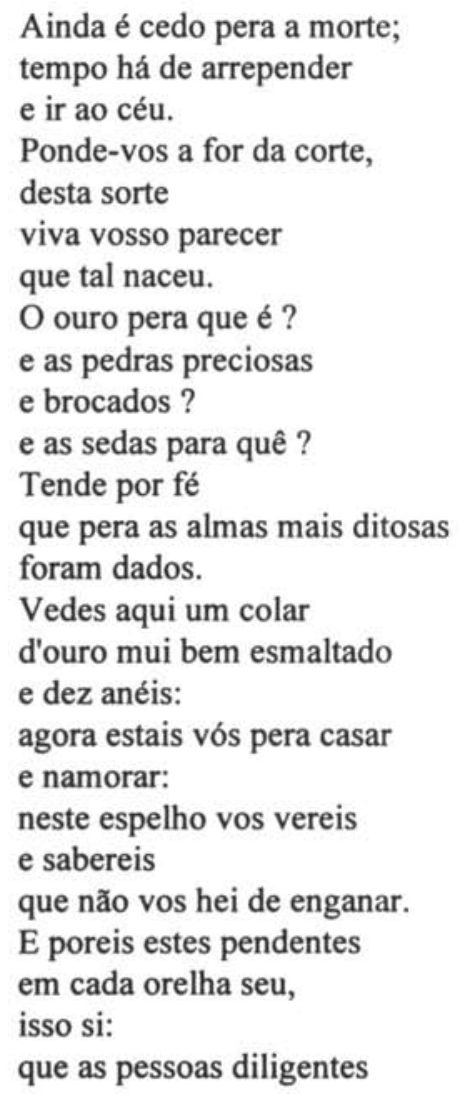


são prudentes.

Agora vos digo eu

que vou contente daqui.

$$
\text { (AA, 24, 25) }
$$

Acontece que o anjo não fica atrás, embora seus objetos sejam de outra configuração, apesar de a natureza ser a mesma: cada qual por sua vez, ambos querem conduzir a alma para seus domínios - e nesse sentido, o anjo também enumera as delícias passíveis de serem desfrutadas pela alma:

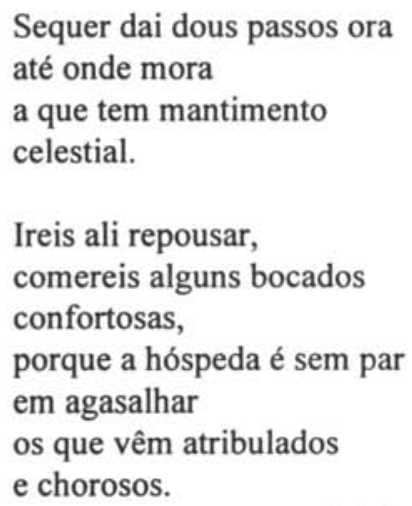

$$
\text { ( AA, 26) }
$$

Naturalmente que o auto é construído para ratificar a vitória do Bem ( representado pelo Anjo ) sobre o Mal ( representado pelo Diabo ), apesar de uma aparente irresolução da Alma no momento em que aceita as prendas que o sedutor das trevas lhe oferece. Acatando as reprimendas do Anjo, a Alma se despoja dos presentes recebidos e recita um mea culpa que ratifica o seu arrependimento e lhe abre as portas do paraíso:

E por minha triste sorte

e diabólicas maldades

violentas, estou mais morta que a morte, sem deporte, carregada de vaidades 
peçonhentas.

(...)

Cada passo me perdi

em lugar de merecer:

eu sou culpada.

( ... )

E, por mais Graveza, sento

não poder-me arrepender

quanto queria;

que meu triste pensamento,

sendo isento,

não me quer obedecer

como soía.

$$
\text { ( AA, 29) }
$$

A sua salvação é finalmente celebrada pelo autor, na medida em que a rubrica final fecha o texto com um LAUS DEO que de modo bastante nítido oferece ao leitor a expressão de alívio e conforto que todos agora experimentam - e é preciso não esquecer que o equilibrio assim restabelecido não deixa de ter uma função política, uma vez que ratifica o status quo: a rendição da alma à religião dominante também pode ser lida como uma rendição do indivíduo ao sistema político dominante. Não percamos de vista que o auto é dedicado "à mui devota rainha dona Lianor". Se agradava à rainha, algo tinha de político, na melhor das hipóteses.

A mesma circunstância do "diálogo de limiar" é o argumento do $3 .^{\circ}$ ato do auto Na aldeia de Guarapari, de José de Anchieta. Novamente se representam a Alma que acabou de deixar o corpo, e as nossas duas já conhecidas alegorias. Neste auto, como em outros, é bastante visível a coincidência com Gil Vicente, cujos textos Anchieta provavelmente já conhecia desde os tempos de estudante em Coimbra. ${ }^{1}$ Este $3 .^{\circ}$ ato tem por título "Pirataraka", que é justamente o nome do índio que acaba de morrer, e cuja alma é assediada pelo Anjo e pelos Diabos, cada um dos quais querendo, mais uma vez, conduzi-la para o céu ou para o inferno. O fragmento a seguir fala de um dos diabos, é auto-explicativo. Diz ele, falando de Pirataraka:

Pois nunca foi batizado

e prezava o antigo nome, 
como pagão abusado.

Pois seja precipitado

nesse fogo que consome.

(NAG, 223 )

A alma, assustada, recorre à Mãe de Deus, no auto chamada apropriadamente de Fupausy:

Fupausy,

lembra-te agora de mi!

Vem, que me estão atacando !

Venha $o$ anjo venerando

Guardar-me deles aqui

e afugentar esse bando.

(NAG, 227)

É preciso reconhecer, neste trecho como em outros, que o catecismo composto pelo mesmo Anchieta já mostrava sua eficácia, uma vez que tendo aprendido quem eram os seus protetores, ${ }^{2} \mathrm{o}$ índio fazia uso desse conhecimento para se livrar do castigo eterno. O interessante é que, nos autos de Anchieta, os diabos têm uma particularidade que os diferencia do diabo da Auto da Alma, embora os aproxime, de certa forma, daqueles dos Autos das barcas. Essa particularidade é o tom moralista que assumem em seu discurso, acusando a alma de não ter cumprido adequadamente com as suas obrigações religiosas e sociais (espancamento da mulher, roubo de vinho, confissões mal feitas, etc.):
Alma: Assim, sabendo a doutrina, não escondi coisa alguma.
D1: Escondeste, sim, ladina !
Fiz-te dizer, por má sina, Umas mentiras, em suma.
Não é verdade que um dia
Cobiçaste algo a mulheres?

$$
\text { (Id., } 226 \text { - 227) }
$$


Mais interessante ainda é uma fala do diabo $\mathrm{n}^{\circ} 3$, que mais parece a de um catequista do que a de um representante do Mal:
Sim, ter-te-á batizado
o padre te abençoando.
Tu porém foste malvado, ofendendo a Deus amado, e a tentação aceitando.

Assim sendo, quando o Anjo aparece, para ajudar, proteger, guardar e aconselhar, ironicamente nada mais acrescenta em termos de maniqueísmo. Como já vimos, também os diabos parecem estar a serviço do Bem, introjetando a idéia de Deus conforme veiculada pelos catequistas cristãos - aliás, explicitamente referenciados como os portadores da única verdade a ser aceita:
Confiai no Criador, aceitando sua lei, com sujeição, com amor. Do padre, vosso instrutor, a doutrina obedecei.

$$
\text { (Id., 231) }
$$

Neste ponto, talvez seja possível interromper as marcações textuais para considerarmos mais verticalmente algumas da instâncias mencionadas. Num breve retrospecto, poderemos estabelecer que, tanto Gil Vicente quanto José de Anchieta, atualizam certos dados do imaginário de sua época, trabalhando com alegorias no sentido de melhor recepção do ideário que veiculam: tanto em um quanto em outro vamos encontrar um embate entre o Bem e o Mal, sendo o primeiro sempre o vencedor.

$\mathrm{O}$ fato, porém, de usarem alegorias para explicitar essa dualidade faz surgir a desconfiança de que nem tudo é tão simples como pode parecer à primeira vista. É preciso que não nos esqueçamos de que, como "forma de expressão"3 de um catolicismo que perdia terreno tanto para um humanismo que se instalava quanto para um protestantismo que se inaugurava, a alegoria usada por Gil Vicente e José de Anchieta tem uma configuração fortemente medieval, isto é, cristã e didática, para seguirmos 
ainda o pensamento de Walter Benjamin, ${ }^{4}$ que aponta portanto para questões que os textos representam de modo bastante adequado: no caso de Gil Vicente, o reforço do poder da Coroa através da submissão a uma lei que aparentemente é metafísica mas que na prática se dá como estratégia de controle da vontade e do pensamento; no caso de José de Anchieta, sem que qualquer desses procedimentos seja negado, algo de mais perverso acabou por ocorrer, uma vez que ele conseguiu tocar num nervo da cultura autóctone - as noções de Bem e de Mal, neste caso representados pelo anjos e pelos demônios.

Só à guisa de curiosidade, permito-me citar um pequeno trecho do livro Terra sem mal, de Helène Clastres:

Segundo Léry, esse lugar de delícias [uns campos cheios de figueiras, onde os índios nada mais faziam senão bailar o dia inteiro], longe de ser acessível a todos, era a recompensa reservada aos melhores: (...) acreditam na imortalidade das almas, mas também crêem firmemente que, após a morte dos corpos, as almas dos que viveram virtuosamente, isto é, segundo eles, que bem se vingaram e comeram muitos dos seus inimigos, vão para trás das montanhas altas e dançam em belos jardins com as almas dos avós. A mesma informação nos dão Claude d'Abbeville e Yves d'Évreux: ascender à terra de "além das montanhas" era reservado aos mais ferozes desses canibais.

(CLASTRES, H. 1978, 30)

Como se vê, o que para o jesuíta era considerado um Mal (a vingança, a ferocidade, o canibalismo), para os índios era a mais perfeita expressão de virtude e de merecimento da "terra sem mal", ou do que podiam conceber como paraíso terrestre. $\mathrm{O}$ uso da alegoria torna-se, portanto, um fator de apagamento de um traço cultural que, escamoteando a diferença, tenta promover uma espécie de europeização do índio, na medida em que o desenraíza, na medida em que tenta aculturá-lo, na medida em que o mata, pelo menos simbolicamente, para lembrarmos a personagem de Lídia Jorge.

As conseqüências aí estão, ao longo dos quase cinco séculos que nos separam dessa época. Não é preciso mencionar muita coisa; um fato apenas deve bastar para que avaliemos melhor os desdobramentos da aculturação: hoje, muitos índios estão se suicidando, e talvez esse grito mudo seja a prova mais eloqüente da recusa de uma cultura à sua própria 
desumanização, ao desmoronamento de suas noções mais elementares, como as de Bem e de Mal, ao contrário dos índios representados por Anchieta, que renegavam seus mitos e seus ritos para abraçarem a fé cristã. Quase cinco séculos depois, os índios se recusam a perder a memória de sua cultura $\mathrm{e}$ insistem, à sua maneira, e a despeito de todos os anjos e de todos os demônios, em continuar a saber como voa um pássaro.

\footnotetext{
ABSTRACT

A study of Auto da alma, by Gil Vicente, and of the "auto" Na aldeia de Guarapari, by José de Anchieta. The use of allegory, a device ideally suited to a theater seeking to bolster the European status quo and thus the continent's position of political and religious hegemony. Taking advantage of Manicheism. The consequences of acculturation: rootlessness and loss of cultural memory.
}

\section{NOTAS}

1 CARDOSO, S. J., A. $1977,14$.

2 ANCHIETA, J, de. Diálogo da fé, p. 124-25 (ver bibl.)

3 BENJAMIN, W. 1984, $184 \mathrm{~s}$.

4 Id. ib., 193

\section{REFERÊNCIAS BIBLIOGRÁFICAS}

ANCHIETA, José de S. J. Diálogo da Fé. São Paulo: Loyola, 1988. . Lírica portuguesa e tupi. Introd., Notas e Tradução versificada do Pe. Armando Cardoso, S. J. São Paulo, 1984. T. 1.

BENJAMIN, Walter. Origem do drama barroco alemão. Trad., apresentação e notas de Sérgio Paulo Rouanet. São Paulo: Brasiliense, 1984.

BERARDINELLI, Cleonice. Antologia do Teatro de Gil Vicente (com Introd. e Estudo crítico ). 2. ed. Rio de Janeiro: Grifo, 1974.

BOSI, Alfredo. Céu, inferno: ensaios de crítica literária e ideológica. São Paulo: Ática, 1988.

. Cultura brasileira: temas e situações. São Paulo: Ática, 1987. 
BUESCU, Maria Leonor Carvalho. (Introdução e Normalização) Compilaçane de todalas obras de Gil Vicente. Lisboa: Imprensa Nacional/Casa da Moeda, 1983. v. 1 e 2.

CARDIM, Fernão. Tratados da terra e gente do Brasil. Introd. de Rodolfo Garcia. Belo Horizonte: Itatiaia / São Paulo: Ed. da USP, 1980.

CARDOSO, S. J. Armando (Tradução versificada, introdução e notas). Teatro de Anchieta. São Paulo: Loyola, 1977.

CHIAMPI, Irlemar. Orealismo maravilhoso. São Paulo: Perspectiva, 1980. CLASTRES, Helène. Terra sem mal. Trad. de Renato Janine Ribeiro. São Paulo: Brasiliense, 1978.

CLASTRES, Pierre. A sociedade contra o Estado. Trad. de Theo Santiago. 4. ed. Rio de Janeiro: Francisco Alves, 1988.

GIUCCI, Guilhermo. Sem fé, lei ou rei; Brasil 1500-1532. Trad. de Carlos Nougué. Rio de Janeiro: Rocco, 1993.

GUERREIRO, M. Viegas. Para a história da literatura popular portuguesa. 2. ed. Lisboa: Instituto de Cultura e Língua Portuguesa, 1983 (Biblioteca Breve ).

HANSEN, João Adolfo. Alegoria. São Paulo: Atual, 1986.

HOLANDA, Sérgio Buarque de. Visão do Paraíso. 5. ed. São Paulo: Brasiliense, 1992.

MARTINS, Manuel Frias. Para uma compreensão e fundamentação teórica do conceito de alegoria literária. Colóquio Letras n. 79, maio/84, p. 7-15.

MATEUS, Osório. Teatro ao corpo de deos. Colóquio Letras n. 95, p. 13-20, jan.fev. 1987.

MÉTRAUX, Alfred, A religião dos tupinambás. Trad., prefácio e notas de Estevão Pinto. 2. ed. São Paulo: Ed. Nacional / Ed. da USP, 1979.

NOGUEIRA, Carlos Roberto F. O diabo no imaginário cristão. São Paulo: Ática, 1986.

PRADO, Décio de Almeida. Teatro de Anchieta a Alencar. São Paulo: Perspectiva, 1993.

REBELLO, Luiz Francisco. O primitivo teatro português. 2. ed. Lisboa: Instituto de Cultura e Língua Portuguesa, 1984. (Biblioteca Breve). SARAIVA, Antônio José. Gil Vicente e o fim do teatro medieval. 4. ed. Lisboa: Gradiva, 1992.

. Para a história da cultura em Portugal. 3. ed. Lisboa: EuropaAmérica, 1972. v. 2. 
SENA, Jorge de. Estudos de Literatura Portuguesa I. Lisboa: Edições 70, 1981.

SOUZA, Laura de Mello E. O diabo e a terra de Santa Cruz. 2. reimp. São Paulo: Companhia das Letras, 1986.

VAINFAS, Ronaldo. Trópico dos pecados. Rio de Janeiro: Campus, 1989.

VASCONCELOS, J. Leite de. Teatro popular português. Coord. e notas de A. Machado Guerreiro. Coimbra: Atlântida, 1976. v. 1.

VICENTE, Gil. Obras completas. Prefácio e Notas de Marques Braga. 5. ed. Lisboa: Sá da Costa, 1974. 